\title{
Weather influences on demography of the yellow-bellied marmot (Marmota flaviventris)
}

\author{
Orlando A. Schwartz ${ }^{1 *}$ and Kenneth B. Armitage ${ }^{2}$ \\ ${ }^{1}$ Department of Biology, University of Northern Iowa, Cedar Falls, IA 50613-0421, U.S.A. \\ ${ }^{2}$ Department of Ecology and Evolutionary Biology, University of Kansas, Lawrence, KS 66045-7534, U.S.A. \\ (Accepted 19 May 2004)
}

\begin{abstract}
Yellow-bellied marmots Marmota flaviventris were live-trapped and marked in the East River Valley of Colorado from 1962 to 1998. For females, static life tables were calculated each year from 1967, when ages were well known, to 1997. Population density was determined, and from life tables calculations were made of: survivorship of young, yearlings and adults; percentage of females producing litters; mean and variance of litter size; net reproductive rate $\left(R_{o}\right)$; and generation length. From climate records a set of 14 annual weather variables was developed that described temperature, precipitation and lengths of growing season and winter. Data from 1981 and 1996 were not used since weather data contained extreme outliers in date of last snow cover. Univariate correlation matrices were calculated among weather variables, among demographic variables, and between weather and demographic variables. Mean temperature in 24 of 29 years was cooler than long-term average temperature. Generation length increased during the years of the study. Weather data were used as independent variables with each dependent demographic variable to calculate nine multiple correlation and regression models. Models explained from $0 \%$ to $58 \%$ of the variation in demography. Significant factors in each model were mostly interpreted as affecting availability of energy necessary for successful hibernation and reproduction.
\end{abstract}

Key words: demography, Marmota flaviventris, marmot, weather, correlation

\section{INTRODUCTION}

The yellow-bellied marmot Marmota flaviventris is a social mammal occupying montane regions of western North America. Growing seasons are typically short, and years with extremes of weather that may affect annual cycles are common. In west central Colorado marmots immerge into hibernation when the vegetation senesces in late summer, typically between late August and midSeptember. Emergence from hibernation varies from year to year (Inouye et al., 2000) and occurs earlier at lower elevations in our study area (Blumstein, Nicodemus \& Zugmeyer, 2004). About $50 \%$ of the marmots emerge from hibernation between 25 April and 7 May (Blumstein et al., 2004). Mating follows emergence, gestation lasts c. 30 days, and young nurse in the burrow for c. 30 days and typically appear above ground in late June or early July. The remainder of the active season is spent accumulating sufficient fat for hibernation and the initiation of reproduction the following year. Young and maternal females may be particularly stressed in acquiring

*All correspondence to: O. A. Schwartz.

E-mail: Orlando.Schwartz@uni.edu fat reserves for hibernation during the $c .2$ months of foraging before vegetation senescence. Reproductive maturity in some females may occur as early as 2 years of age.

A 32-year demography of yellow-bellied marmots (Schwartz, Armitage \& Van Vuren, 1998) revealed that marmots have a type II (Krebs, 2001) survivorship pattern with annual mortality from c. $25 \%$ to $50 \%$ for all age classes of both sexes. Young typically hibernate in the natal colony and most yearlings disperse. By 2 years of age all males and half of females have dispersed from their natal colony. Net reproductive rate $\left(R_{o}\right)$ was 0.85 , which would imply a declining population. Numbers of marmots over 32 years fluctuated approximately fourfold, but immigration from habitats other than our study sites prevented declines in densities. Predation is high with at least six species of predators killing marmots for prey (Van Vuren, 2001), and weather is a major source of mortality. Variation in weather can favourably or unfavourably impact the demography of marmots.

In spring, marmots must emerge from hibernation early enough to have sufficient time for reproduction and for reproductive females and young to accumulate adequate fat stores to survive hibernation (Armitage, 1991, 1999). Energy depletion can lead to hibernation mortality for 
marmots with insufficient fat reserves (Armitage, 1994). If vernal weather is stressful (e.g. low temperatures, late snow cover), the animals may deplete fat stores to the point where reproduction is impossible. In effect, marmots gamble energetically in their anticipation that food will become available (French, 1990). In our study area most marmots emerge through the snow before the onset of plant productivity (Svendsen, 1974; Inouye et al., 2000). Some plant growth begins beneath shallow snow cover (Svendsen, 1974), but growth is not significant until after snowmelt (Inouye et al., 2000). Normally, forage is available during gestation, is abundant during lactation, and reaches peak biomass after young are weaned. However, a 7-year study found that the later the date of snow melting, measured as the date of $50 \%$ bare ground, the lower the frequency of reproduction, the smaller the litter size, and the smaller the body mass of young on 1 August (Van Vuren \& Armitage, 1991).

Weather during the active season of marmots may influence fat deposition as marmots prepare for autumn hibernation. In 1991, late snow melt and low summer precipitation adversely affected juvenile mortality (Armitage, 1994; Lenihan \& Van Vuren, 1996). Mortality may have been affected by differences in microclimate among colony sites owing to altitudinal differences between lower and higher colonies (Armitage, 1994). Colonies at higher elevations weaned their young as much as 21 days later (Salsbury \& Armitage, 2003). Mass gain for most marmots is continuous during the summer except for parous females that begin mass gain after weaning (Armitage, Downhower \& Svendsen, 1976; Armitage, 1996a; Salsbury \& Armitage, 2003). Marmots receive all nutrition from plants, and plant biomass typically declines in the month before hibernation (Kilgore \& Armitage, 1978; Frase \& Armitage, 1989). Temperature is a major factor determining the standard operating temperature of marmots (Melcher, Armitage \& Porter, 1990). Thus, unseasonably warm or cool summers could increase thermal stress and markedly affect mass gain and survival. Young are much more negatively affected by high temperature than are adults (Melcher et al., 1990). High temperature reduces the time during the day available for foraging and thus decreases fat accumulation for hibernation.

Amount and timing of precipitation are important factors affecting demography. Low precipitation in the active season negatively affects survivorship and reproduction (Armitage, 1994; Lenihan \& Van Vuren, 1996). There is probably little negative effect in a year with high rainfall. Mean and variance of monthly precipitation are highly correlated (see Results) in the continental and montane climate of the study area.

Marmots typically hibernate in late August or early September. At that time fat reserves must be sufficient for hibernation of up to 8 months. Immergence of young marmots occurs from 1 to 3 weeks later than for adults (Kilgore \& Armitage, 1978). Thus, young are more likely to be affected by any weather factors impacting mass gain in late summer. Senescence of vegetation typically occurs by early September, except for some late summer composites and gentians that are not used for food by marmots. A shorter active season reduced survivorship; marmots hibernated at lower body masses and lower energy reserves (Armitage, 1994). In our study area, marmots usually hibernate in late August or early September before there is any snow cover. Thus, autumnal snowfall or snow cover should not affect survival as long as snow cover occurs before temperatures can reduce burrow temperatures below $5{ }^{\circ} \mathrm{C}$. These low burrow temperatures increase metabolic rate, which could deplete fat stores and increase mortality. Young are more strongly affected than adults (Armitage, Blumstein \& Woods, 2003).

In this paper the relationship between demography and weather variables from 29 years of data are systematically examined and univariate and multiple correlation and regression analyses are used to show proportions of demography explained by weather. We hypothesize that the effects of annual weather variation would principally affect the energy necessary for surviving hibernation and for reproduction. Predation and loss by dispersal would be less affected by weather.

\section{METHODS}

From 1962 to 1998, yellow-bellied marmots were studied in the East River Valley c. $15 \mathrm{~km}$ north of Crested Butte, Colorado. Each year nearly all marmots were live-trapped and given numbered ear tags for identification. For this study only data from a core area in which nearly all resident marmots were captured each year were used. Numbers from this core area are here referred to as population density.

Climate in the study area is montane and continental. Elevation ranges from 2867 to $2992 \mathrm{~m}$. For the years of this study average temperatures for the 6-month active season of marmots ranged from 6.2 to $8.1^{\circ} \mathrm{C}$, and annual precipitation varied from 38 to $87 \mathrm{~cm}$. Habitat is forested with quaking aspen Populus tremuloides, spruce Picea engelmanni, and willow Salix sp. as the dominant woody vegetation. Marmots form social colonies in discontinuously distributed montane meadows dominated by Festuca thurberi, Bromus, Poa and numerous forbs (Svendsen, 1974). Meadows inhabited by marmots range from 0.01 to 7.2 ha.

\section{Weather variables}

Weather data were obtained for Crested Butte, Colorado, which is $c .10 \mathrm{~km}$ from the study site (Anonymous, 1966-97). From these records 14 weather variables were obtained or calculated to use as independent variables in univariate and multiple correlation models:

Temperature: Mean (1) and variance (2) of the average temperature and mean deviation from normal temperature (3) for April to October. Deviation from normal temperature is provided in Climatological Data and is a mean of a 30-year period that is updated in years that end with the number 2 and therefore may lag the current year by $2-12$ years. For example, for 1975 and 1981 the normal 
years are 1941-1970; for 1982 and 1991 the normal years are 1951-1980.

Precipitation: For each year a mean (4) and variance (5) of monthly precipitation was calculated from data beginning at the end of one marmot year, October, to the following October.

Snowfall: Julian dates were obtained for the last permanent snow cover of $2.54 \mathrm{~cm}$ (6) and the last snowfall (7) that occurred from April to early June and the first snowfall (8) and first permanent snow cover of $2.54 \mathrm{~cm}$ (9) that occurred between mid-September and early December. For 1981 the last snow cover was 52 days into the year and for 1996 there was no last date of snow cover (range of other years 94-136 days). These outlying points unduly skewed statistical calculations and all data from these years were not used in this study.

Growing season: The number of frost-free days (10), where temperatures remained above $0{ }^{\circ} \mathrm{C}$ were obtained from the records. Growing season I (11) was calculated as the date of the first snowfall minus the date of the last snowfall. Similarly, growing season II (12) was determined from dates of the first minus the last snow cover. Length of growing season and number of frost-free days may index the duration of plant availability before plant senescence and therefore the time to fatten before hibernation.

Winter length: Winter length I (13) was the number of days from the first snowfall the previous year to the last snowfall of the current year. Winter length II (14) was the number of days from the first snow cover of the previous year to the last snow cover in the current year. Winter length I and II may index the duration of hibernation and the period marmots rely on fat stores.

\section{Demographic variables}

To develop dependent demographic variables, annual static life tables were calculated following Krebs (2001) from 1967, when ages of marmots were well known, to 1997. Mortality means disappearance from the study area. Trapping data from the 1998 season were used to determine survivorship for the 1997 life table. Nine dependent variables developed included population density (1) from the core of the study area, and from the mortality side of life tables: survival rates of young (2), yearlings (3) and adults (4). From maternity data the per cent of females that reproduced was determined, called here per cent maternity (5), and the mean (6) and variance (7) of litter size. Net reproductive rate $\left(R_{o} ; 8\right)$ and generation length $(G ; 9)$ were calculated from mortality and maternity data.

\section{Statistical methods}

Univariate correlation matrices were calculated using year and all weather variables, using year and all demographic variables, and between weather and demographic variables. To avoid making type I errors among weather correlations we choose $\alpha=0.01$ (105 correlations), among demographic variables $\alpha=0.02$ (44 correlations), and between weather and demographic variables $\alpha=0.01$ (112 correlations).

Multivariate correlation and regression model development followed Sokal \& Rohlf (1995) and SAS (1999). Models were developed for each dependent demographic variable and independent weather variables that were appropriate to that variable, e.g. the first snowfall and first snow cover could not affect reproductive variables. Maximum $R^{2}$ models were calculated using $\alpha<0.05$ for $F \mathrm{~S}$ to enter and $\alpha<0.10$ for $F \mathrm{~s}$ to remove (Sokal \& Rohlf, 1995). Best-fit models were chosen where the $F$-test statistic was greatest and the associated probability the least $(P<0.05$ in all instances). The sign of the regression coefficient for variables is reported here with partial correlation coefficients to show the sign of correlations. Independent variables in the models chosen were interpreted as sets of data since independent variables in models are developed by varying 1 factor while other factors are held constant.

\section{RESULTS}

\section{Weather variables}

No weather variable was correlated with year, hence these data reveal no climate trend for the years of this study. Mean temperature and deviation from mean temperature were correlated $(r=0.89$, for all weather correlations d.f. $=27, P<0.01) ; 24$ of 29 years of the study were cooler than long-term averages (Fig. 1). Years with a high variance in precipitation also had high mean monthly precipitation $(r=0.67)$. Growing season I was correlated with and derived from last snow $(r=-0.68)$ and first

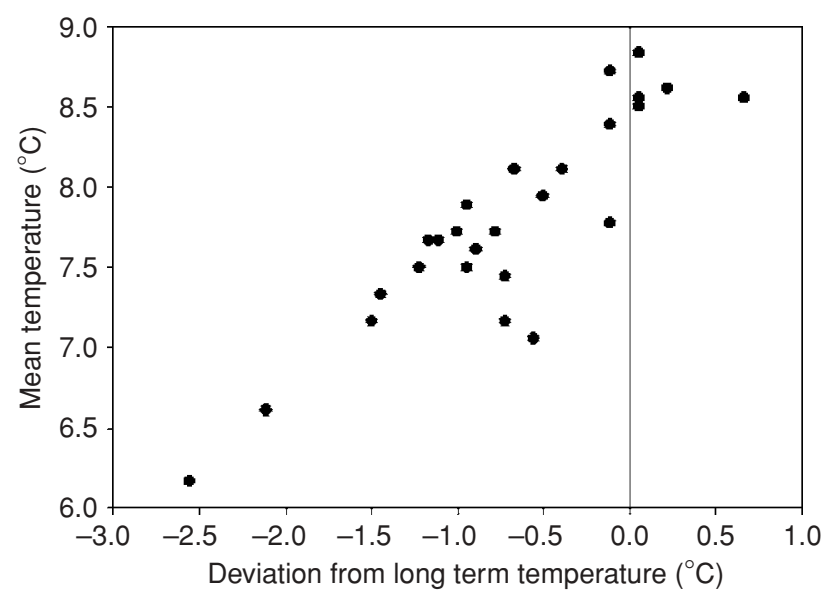

Fig. 1. Mean deviation from long-term temperature and mean temperature are calculated using data from Climatological Data for April-October. Only 5 of 29 years of the study were above the long-term average. 
Table 1. Univariate correlations between year and among demographic parameters of yellow-bellied marmots Marmota flaviventris from 1967 to 1997 (with 1981 and 1996 excluded). $R_{o}=$ net reproductive rate; $G=$ generation length. ${ }^{* *}, P<0.02 ;{ }^{* * *}, P<0.01$

\begin{tabular}{|c|c|c|c|c|c|c|c|c|c|}
\hline & \multirow[b]{2}{*}{ Density } & \multicolumn{3}{|c|}{$\%$ survival } & \multicolumn{2}{|c|}{ Litter size } & \multirow[b]{2}{*}{$R_{o}$} & \multirow[b]{2}{*}{$G$} & \multirow[b]{2}{*}{ Per cent maternity } \\
\hline & & Young & Yearling & Adult & Mean & $\mathrm{S}^{2}$ & & & \\
\hline Year & & & & & & & & $0.54^{* *}$ & \\
\hline Density & 1.00 & & & & & & $0.71^{* * *}$ & & \\
\hline \multicolumn{10}{|l|}{ Survival } \\
\hline Young & & 1.00 & $0.81^{* * *}$ & $0.56^{* *}$ & & & & & \\
\hline Yearling & & & 1.00 & $0.64^{* * *}$ & & & & & \\
\hline Adult & & & & 1.00 & & & & & \\
\hline \multicolumn{10}{|l|}{ Litter size } \\
\hline Mean & & & & & 1.00 & & $0.56^{* *}$ & & \\
\hline $\mathrm{S}^{2}$ & & & & & & 1.00 & & & \\
\hline$R_{o}$ & & & & & & & 1.00 & $0.48^{* *}$ & $0.51^{* *}$ \\
\hline$G$ & & & & & & & & 1.00 & \\
\hline
\end{tabular}

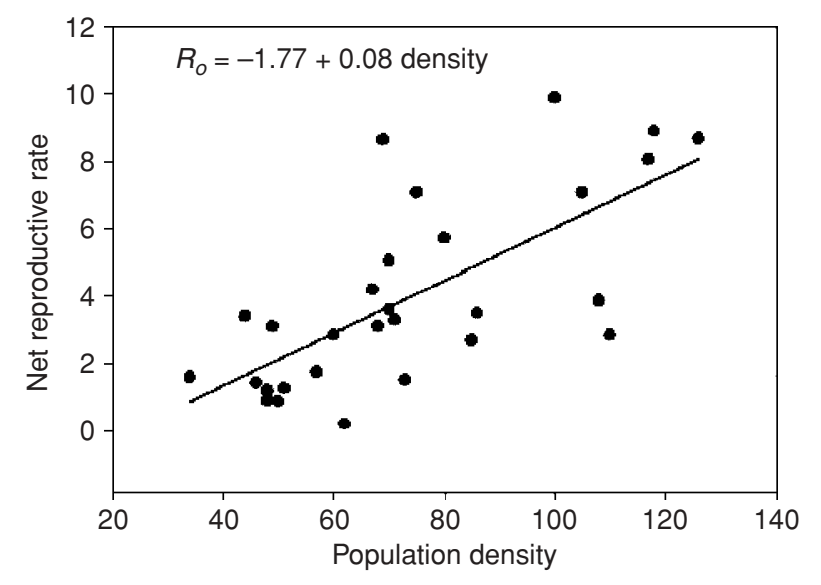

Fig. 2. Regression between population density and net reproductive rate $\left(R_{o}\right)$ showing a density-dependent relationship in yellow-bellied marmots Marmota flaviventris.

snow $(r=0.69)$. The growing season was shorter the later the last snow occurred in the spring and the earlier the first snow occurred in autumn. Similarly, growing season II was correlated with and derived from last snow cover $(r=-0.78)$ and first snow cover $(r=0.74)$. Winter length I was correlated with last snow $(r=0.59)$, but not first snow, indicating its length was most affected by the timing of spring snow rather than the first snow in the fall.

\section{Demographic variables}

A correlation matrix of demographic variables (Table 1) showed that generation length $(G)$ increased during the years of the study $(r=0.54$, d.f. $=27, P<0.02)$ and a significant regression was found $\left(G=-0.96+0.09^{*}\right.$ year, $\left.F_{1,27}=11.24, P=0.0024\right)$. A positive correlation between $R_{o}$ and density showed a density-dependent relationship between the two variables and a significant regressions was found $\left(R_{o}=-1.77+0.08^{*}\right.$ density, $F_{1,27}=$ 26.81, $P<0.0001$ ) (Fig. 2). Net reproductive rate was also positively correlated with and derived from aspects of mean litter size and per cent maternity. Generation length was correlated with $R_{o}$, which is in the denominator of its calculation.

No univariate correlations between weather and demographic variables were significant at $P<0.01$.

\section{Multiple correlations}

All weather factors except variance of temperature and date of first snow cover were used in the nine multiple correlation and regression models (Table 2). In these models significant partial correlation coefficients of temperature measurements and date of first snowfall were most common. No models could be fit for yearling survival or mean litter size. A set of four factors, mean temperature, a negative correlation with deviation from normal temperature, variance of precipitation, and last snowfall, accounted for $41 \%$ of the variation in marmot densities.

Thirty-three per cent of the variation in survival of young was explained by three factors, a negative correlation with mean temperature, deviation from normal temperature, and first snowfall. Winter length II accounted for $14 \%$ of the variation in adult survival. Three factors, mean temperature, total precipitation, and a negative correlation with number of frost-free days, explained 34\% of the variation in variances of litter sizes. First snowfall explained $18 \%$ of the variation in net reproductive rate. For generation length, partial correlations were found with deviation from normal temperature, variance in precipitation, last snow cover, first snowfall, winter length I, and a negative correlation with winter length II; $58 \%$ of the variation was explained. For per cent maternity, 38\% of the variation was explained by mean temperature, deviation from normal temperature, total precipitation, last snowfall, and growing season II.

\section{DISCUSSION}

Multivariate weather models were useful in explaining components of demographic variation in yellow-bellied marmots. The annual fluctuations of demographic (Schwartz \& Armitage, 1998) and weather variables were 


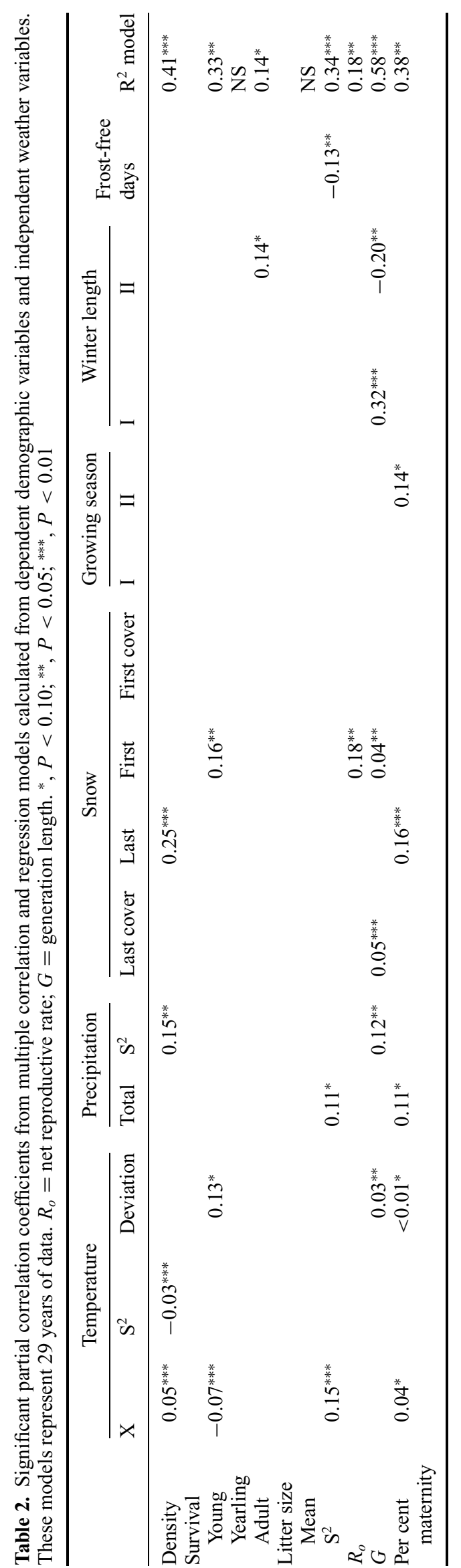

great, so the explanatory power of univariate correlations was poor. No climatic trends were evident over the years of the study.

Though many weather stations have reported climate warming during the years of our study, warming was not found in these weather data. From our study area, Inouye et al. (2000) describe climate impacts on plant phenology, date of robin Turdus migratorius arrival in spring, and dates of marmot emergence from hibernation that were consistent with climate warming. However, the air temperature and snowfall data that they presented, as with our study, showed no significant linear trends over the 23 years of their study. Although $83 \%$ of the years of this study were cooler than long-term averages, in this study the results are interpreted as the annual effects of weather variation rather than as part of a climatic trend.

Approximately $41 \%$ of the variation in marmot density was explained by weather variables (Table 2). As a set of variables, a favourable marmot year would have a moderate temperature in the active season as shown by the positive and negative signs of partial correlation coefficients of mean temperature and deviation from normal temperature, respectively. A positive correlation between density and variance of precipitation, which was correlated with total precipitation, showed the benefit of a year of favourable primary productivity. A positive correlation with last snowfall may indicate that lack of snow cover in the spring is detrimental or that late snow is a timely source of moisture for plant growth.

Univariate correlations among survivorship of young, yearlings, and adult marmots is high (Table 1). Certainly many of the same weather factors affect each age class. Weather accounted for 33\% of variation in survivorship of young (Table 2). Survivorship of young has a negative partial correlation with mean temperature and a positive partial correlation with deviation from longterm temperature that was cooler than normal (Fig. 1). The balance of the two correlations suggests that an active season without extreme temperatures favours young survival. First snowfall was positively correlated with survivorship of young. As suggested below for net reproductive rate, a later first snowfall is associated with a longer growing season that allows young marmots greater opportunities to build sufficient fat reserves for hibernation.

No model could be fit for yearling survival. Most of the disappearance of yearlings from the study area is at least initially the result of dispersal of all males and half of females. Social factors rather than weather affect dispersal (Downhower \& Armitage, 1981). Subsequent predation on dispersers is high (Van Vuren \& Armitage, 1994) and is not weather related.

Winter length II explained 14\% of adult survivorship (Table 2); longer snow cover may prevent burrow temperatures from reaching stressful levels or prevent early arousal and onset of euthermic metabolism. Either of these would decrease energy reserves and increase mortality. The low percentage of variation explained suggests that the adult age class is less vulnerable to weather effects. 
Mean litter size was not correlated with any weather variable, but three weather factors explained $34 \%$ of variance of litter sizes (Table 2). Sources of variation in litter sizes are complex. Years with broadly favourable breeding weather (longer growing season with warm temperatures, adequate precipitation) would allow females in marginal condition to reproduce but with lower litter sizes than females in better condition, thus increasing variation. Colder years or years with insufficient precipitation probably permit only females in better condition to reproduce, thus lowering variances of litter size. A negative correlation with frost-free days suggests that as the length of the growing season decreases, litter sizes are more variable. Again, females in poorer condition are unlikely to support normal-sized litters.

Net reproductive rate $\left(R_{o}\right)$ was positively correlated with population density. During periods of from 1 to several years when weather is favourable and predation is low, population density increases by the addition of new members to matrilines (Armitage, 1996b) and by the formation of new matrilines (Armitage, 1984, 1986, 1989) as large matrilines divide to form smaller matrilines. $R_{o}$ increases as matriline size increases then decreases in the largest matrilines (Armitage \& Schwartz, 2000) and the division of large matrilines into smaller matrilines restores high $R_{o}$. The most successful matrilines are those in which a large proportion of the adult females reproduce (Armitage, 2003). Although older females may suppress the reproduction of younger females, when older, dominant females are absent, females are more likely to reproduce when same age or younger adult females are present (Armitage, 2003). Thus the relationship between $R_{o}$ and population density is linked through the dynamics of the social system in which it is more likely that a greater proportion of females reproduce in small matrilines where group membership facilitates breeding.

Date of first snowfall explained $18 \%$ of the variation in $R_{o}$ (Table 2). $R_{o}$ is the sum of the product of survivorship of all females and birth rate for each age class. Number of young produced early in the season cannot be affected by date of first snowfall, so this weather variable must act on the survivorship components of $R_{o}$. Because no births occur before females are 2 years old, young and yearling age classes add zeros to the sum of this statistic. A later first snowfall may indicate a longer growing season that would especially benefit reproductive females, who begin mass gain almost 3 weeks later than other adults (Armitage, $1996 a$ ), by providing more time for mass gain.

Among demographic data only generation length increased during the years of the study (Table 1) with a regression line increasing from 4.5 years in 1967 to nearly 7 years in 1997. Six weather variables in the model of generation length $(G)$ accounted for $58 \%$ of the variation in this statistic (Table 2). Generation length is calculated from the summed product of survivorship, birth rate, and age class, which is then divided by $R_{o}$. Larger numerators that increase $G$ occur when greater proportions of young are produced by older age class animals. The increase in $G$ over the years of the study implies more favourable conditions for survivorship and reproduction by younger age classes in the earlier years of this study and by older age classes in later years. With the complexity of the relationships among six factors and a statistic that is a synthesis of survivorship, birth rate, and age class, no attempt is made to break down these relationships.

Per cent maternity was explained by five variables that accounted for $38 \%$ of the observed variation (Table 2 ). A positive relationship with total precipitation suggests that maternity increases with both adequate snow cover during hibernation and adequate forage during the active season. Growing season II is longer when snow melts earlier in the spring. Earlier snow melt is related to earlier plant growth; thus energy becomes available earlier in the season to all adult females and enables more of them to reproduce. Females that cannot access early forage and must rely on remaining fat reserves have a smaller probability of reproducing (Andersen, Armitage $\&$ Hoffman, 1976). Positive and negative correlations with mean temperature and deviation from normal temperature, respectively, explained little of the variation (Table 2). Possibly these are related to early snow melt or to the termination of hibernation (Inouye et al., 2000). Either of these would lengthen the active season and increase per cent maternity. The positive relationship with last snowfall may indicate favourable moisture and palatable forage.

An optimal weather season for marmots would have temperatures that were moderate to warm. Years of warmer temperatures showed increased density, per cent maternity, and variance in litter size. This pattern suggests that warmer temperatures increased survival and the number of females reproducing. Increased precipitation benefited densities and reproduction. Positive and negative correlations with snowfall, growing season, and winter length measurements suggest that there is an optimal range for the active season of marmots. The mechanism by which annual weather variation affects population dynamics of marmots is by acting on the critical balance of energy required to survive hibernation and to commence reproduction in the spring. Marmots occupy a niche in the study area as a herbivore and hibernator in a habitat with a short growing season. Although marmots may be locally abundant, the weighted annual average of mortality from all age classes from all causes averages $42 \%$ for females and 53\% for males (from Schwartz et al., 1998). There is a fivefold difference in the highest and lowest annual death and reproductive rates (Schwartz \& Armitage, 1998). Both survivorship and reproduction depend on access to forage for essential nutrients and energy. The annual energy budget of marmots is substantially affected, both positively and negatively, by variations in and interactions with weather. Sociality in marmots is an adaptation to the rigours of this high montane climate (Armitage, 1999).

\section{Acknowledgements}

Field work was conducted at the Rocky Mountain Biological Laboratory and supported by grants from NSF. We thank the many dedicated students and technicians whose assistance made this work possible. The University 
of Northern Iowa provided a sabbatical leave to OAS for this research. We thank M. Ecker of the University of Northern Iowa Mathematics Department for critical statistical advice.

\section{REFERENCES}

Andersen, D. C., Armitage, K. B. \& Hoffmann, R. S. (1976). Socioecology of marmots: female reproductive strategies. Ecology 57: 552-560.

Anonymous (1966-97). Climatological data annual summary, Colorado. Washington, D.C.: National Oceanic and Atmospheric Administration.

Armitage, K. B. (1984). Recruitment in yellow-bellied marmot populations: kinship, philopatry, and individual variability. In Biology of ground-dwelling squirrels: 377-403. Murie, J. O. \& Michener, G. R. (Eds). Lincoln: University of Nebraska Press.

Armitage, K. B. (1986). Marmot polygyny revisited: determinants of male and female reproductive strategies. In Ecological aspects of social evolution: 303-331. Rubenstein, D. S. \& Wrangham, R. W. (Eds). Princeton, NJ: Princeton University Press.

Armitage, K. B. (1989). The function of kin discrimination. Ethol. Ecol. Evol. 1: 111-121.

Armitage, K. B. (1991). Social and population dynamics of yellowbellied marmots: results from long-term research. Annu. Rev. Ecol. Syst. 22: 379-407.

Armitage, K. B. (1994). Unusual mortality in a yellow-bellied marmot population. In Actual problems of marmot investigations: 5-13. Rumiantsev, V. Y. (Ed.). Moscow: A. B. F. Publishing House. [Available from the authors.]

Armitage, K. B. (1996a). Seasonal mass gain in yellow-bellied marmots. In Biodiversity in marmots: 223-226. LeBarre. M., Ramousse, R. \& LaGuelte, L. (Eds). Lyon/Moscow: International Marmot Network. [Available from the authors.]

Armitage, K. B. (1996b). Social dynamics, kinship and population dynamics of marmots. In Biodiversity in marmots: 113-128. LeBarre. M., Ramousse, R. \& LaGuelte, L. (Eds). Lyon/Moscow: International Marmot Network. [Available from the authors.]

Armitage, K. B. (1999). Evolution of sociality in marmots. J. Mammal. 80: 1-10.

Armitage, K. B. (2003). Reproductive competition in female yellowbellied marmots. In Adaptive strategies and diversity in marmots: 133-142. Ramousse, R., Allaine, D. \& Le Berre, M. (Eds). Lyon: International Network on Marmots. [Available from the authors.]

Armitage, K. B., Blumstein, D. J. \& Woods, B. C. (2003). Energetics of hibernating yellow-bellied marmots (Marmot flaviventris). Comp. Biochem. Physiol. A 134: 101-114.

Armitage, K. B., Downhower, J. F. \& Svendsen, G. E. (1976). Seasonal changes in weights of marmots. Am. Midl. Nat. 96: $36-51$.
Armitage, K. B. \& O. A. Schwartz. (2000). Social enhancement of fitness in yellow-bellied marmots. Proc. natl Acad. Sci. U.S.A. 97: 12149-12152.

Blumstein, D. T., Im, S., Nicodemus, A. \& Zugmeyer, C. (2004). Yellow-bellied marmots (Marmota flaviventris) hibernate socially. J. Mammal. 85: 25-29.

Downhower, J. F. \& Armitage, K. B. (1981). Dispersal of yearling yellow-bellied marmots (Marmota flaviventris). Anim. Behav. 29: 1064-1069.

Frase, B. A. \& Armitage, K. B. (1989). Marmots are generalist herbivores. Ethol. Ecol. Evol. 1: 353-366.

French, A. (1990). Age-class differences in the pattern of hibernation in yellow-bellied marmots, Marmota flaviventris. Oecologia (Berl.) 82: 93-96.

Inouye, D. W., Barr, B., Armitage, K. B. \& Inouye, B. D. (2000) Climate change is affecting altitudinal migrants and hibernating species. Proc. natl Acad. Sci. U.S.A. 97: 1630-1633.

Kilgore, D. L. Jr \& Armitage, K. B. (1978). Energetics of yellowbellied marmot populations. Ecology 59: 78-88.

Krebs, C. J. (2001). Ecology: the experimental analysis of distribution and abundance. San Francisco, CA: Benjamin Cummings.

Lenihan, C. \& Van Vuren, D. (1996). Growth and survival of juvenile yellow-bellied marmots (Marmota flaviventris). Can. J. Zool. 74: 297-302.

Melcher, J. C., Armitage, K. B. \& Porter, W. P. (1990). Thermal influence on the activity and energetics of yellow-bellied marmots. Physiol. Zool. 63: 803-820.

Salsbury, C. M. \& Armitage, K. B. (2003). Variation in growth rates of yellow-bellied marmots (Marmota flaviventris). In Adaptive strategies and diversity in marmots: 197-206. Ramousse, R., Allaine, D. \& Le Berre, M. (Eds). Lyon: International Network on Marmots. [Available from the authors.]

SAS (1999). SAS ${ }^{\circledR}$ Procedures guide, version 8. Cary, NC: SAS Institute.

Schwartz, O. A., Armitage, K. B. \& Van Vuren, D. (1998). A 32-year demography of yellow-bellied marmots. J. Zool. (Lond.) 246: 337-346.

Schwartz, O. A. \& Armitage, K. B. (1998). Empirical considerations on the stable age distribution. Oecologia Montana 7: 1-6.

Sokal, R. R. \& Rohlf, F. J. (1995). Biometry. New York: W. H. Freeman.

Svendsen, G. E. (1974). Behavioral and environmental factors in the spatial distribution and population dynamics of a yellow-bellied marmot population. Ecology 55: 760-776.

Van Vuren, D. (2001). Predation on yellow-bellied marmots. Am. Midl. Nat. 145: 94-100.

Van Vuren, D. \& Armitage, K. B. (1991). Duration of snow cover and its influence on life-history variation in yellow-bellied marmots. Can. J. Zool. 69: 1755-1758.

Van Vuren, D. \& Armitage, K. B. (1994). Survival of dispersing and philopatric marmots: what is the cost of dispersal? Oikos 69: 179-181. 